\title{
Parental and child factors associated with inhalant and food allergy in a population-based prospective cohort study: the Generation $\mathbf{R}$ Study
}

\author{
Nicolette W. de Jong ${ }^{1}$ • Niels J. Elbert ${ }^{2,3}$ - Sara M. Mensink-Bout ${ }^{4,5}$ • Johanna P. M. van der Valk ${ }^{1}$ • \\ Suzanne G. M. A. Pasmans ${ }^{1} \cdot$ Vincent W. V. Jaddoe $^{2,4,6} \cdot$ Johan C. de Jongste $^{5} \cdot$ Roy Gerth van Wijk $^{1} \cdot$ Liesbeth Duijts $^{5,7}$
}

Received: 6 December 2018 / Revised: 9 July 2019 / Accepted: 6 August 2019 / Published online: 15 August 2019

(C) The Author(s) 2019

\begin{abstract}
The prevalence of allergic diseases in children is markedly increasing to epidemic proportions. The aim of this study is to describe the presence and examine associated parental and child characteristics of allergic sensitization and physician-diagnosed allergy in Dutch children at age 10 years. This study among 5471 children was performed in a population-based prospective cohort from fetal life onwards. Allergic sensitization was measured by skin prick tests. Physician-diagnosed allergy and parental and child characteristics were collected by questionnaires. In children aged 10 years, inhalant and food allergic sensitization was present in $32.2 \%$ and $7.1 \%$, and physician-diagnosed inhalant and food allergy in $12.4 \%$ and $2.3 \%$. Maternal and paternal history of allergy, eczema or asthma was associated with increased risks of physician-diagnosed inhalant allergy (aOR (95\% CI) 1.44 (1.23-1.70) and 1.59 (1.30-1.94), respectively), but not with food allergy. Asthma and eczema ever at age 10 years were associated with increased risks of physician-diagnosed inhalant allergy (4.60 (3.55-5.96) and 2.42 (1.94-3.03), respectively). Eczema ever at age 10 years was associated with an increased risk of physician-diagnosed food allergy $(5.78,3.04-9.52)$, with the highest risk of cashew $(7.36,3.20-16.94)$ and peanut $(5.58,3.08-10.10)$ food allergy.
\end{abstract}

Communicated by Nicole Ritz

Electronic supplementary material The online version of this article (https://doi.org/10.1007/s00431-019-03441-5) contains supplementary material, which is available to authorized users.

Nicolette W. de Jong

n.w.dejong@erasmusmc.nl

Niels J. Elbert

niels_elbert@hotmail.com

Sara M. Mensink-Bout

s.mensink-bout@erasmusmc.nl

Johanna P. M. van der Valk

h.kuipervandervalk@gmail.com

Suzanne G. M. A. Pasmans

s.pasmans@erasmusmc.nl

Vincent W. V. Jaddoe

v.jaddoe@erasmusmc.nl

Johan C. de Jongste

j.c.dejongste@erasmusmc.nl

Roy Gerth van Wijk

r.gerthvanwijk@erasmusmc.nl
Liesbeth Duijts

1.duijts@erasmusmc.nl

1 Department of Internal Medicine, Division of Allergology, Erasmus Medical Center, Room Gk 323, P.O. Box 2040, 3000

CA Rotterdam, The Netherlands

2 The Generation R Study Group, Erasmus Medical Center, Rotterdam, The Netherlands

3 Department of Dermatology, Erasmus Medical Center, Rotterdam, The Netherlands

4 Department of Pediatrics, Erasmus Medical Center, Rotterdam, The Netherlands

5 Department of Pediatrics, Division of Respiratory Medicine, Erasmus Medical Center, Rotterdam, The Netherlands

6 Department of Epidemiology, Erasmus Medical Center, Rotterdam, The Netherlands

7 Department of Pediatrics, Division of Neonatology, Erasmus Medical Center, Rotterdam, The Netherlands 
Conclusions: We found strong effects of parental history of allergy, eczema or asthma on the presence of physician-diagnosed inhalant allergy in children at age 10 years. Eczema ever at age 10 years was a strong risk factor for the development of physiciandiagnosed inhalant and food allergy.

What is Known:

- The prevalence of allergic diseases in children has markedly increased.

- Early-life influences are critically important in the development of allergic diseases.

What is New:

- Maternal and paternal history of allergy, eczema or asthma is associated with increased risks of physician-diagnosed inhalant allergy but not with food allergy.

- Eczema ever at age 10 years is associated with an increased risk of physician-diagnosed food allergy, with the highest risk for cashew and peanut food allergy.

Keywords Atopic diseases $\cdot$ Birth cohort $\cdot$ Children $\cdot$ Risk factors

\section{Abbreviations \\ aOR Adjusted odds ratio \\ BMI Body mass index \\ CI Confidence interval \\ HDM House dust mite \\ IgE Immunoglobulin E}

\section{Introduction}

The prevalence of allergic diseases, including inhalant and food allergies, in children has markedly increased to epidemic proportions [25, 29], for which the reasons are not fully clear. Childhood allergic diseases may affect the quality of life, because children with an allergic disease receive more medication and visit a family physician or hospital more frequently than children without an allergic disease [24]. Furthermore, allergic diseases have great social and economic impact both on individuals and their family members [25]. A recent register-based study in Danish and Swedish children showed that the lifetime prevalence at age 10 years of asthma and allergic rhinitis was $15.6 \%$ and $20.4 \%$, respectively [15].

Recently, results from the PASTURE cohort study showed a distinct group of children with severe atopy characterized by high specific immunoglobulin E (IgE) levels and a strong propensity for asthma, hay fever, eczema and impaired lung function [16]. Furthermore, a recent review on European children until age 17 reported a prevalence of symptoms combined with allergic sensitization to at least one allergen of $3.6 \%$ [23].

Factors associated with the development of allergic diseases are not yet fully understood, but parental pet keeping and history of atopy showed to have a certain effect [21, 22]. Moreover, it is suggested that most children with allergic diseases start to have symptoms in early life and that early-life influences are critically important in the development of allergic diseases [1].

Studies on inhalant and food allergy in Dutch children are scarce. One study reported sensitization to inhalant allergens in $19.1 \%$ of 512 Dutch children [35], and another study reported food allergy, measured with questionnaires, in $7.2 \%$ of Dutch children [6].

So far, there are no large prospective cohort studies on presence and associated factors for the development of allergic sensitization and allergy in Dutch children.

We aimed to study the presence of inhalant and food allergic sensitization and physician-diagnosed inhalant and food allergy in Dutch children at age 10 years and its association with parental and child characteristics.

\section{Methods}

General design The Generation R study is designed to identify early environmental and genetic causes and causal pathways leading to normal and abnormal growth, development and health from fetal life, childhood and young adulthood. Pregnant women with an expected delivery date between April 2002 and January 2006 living in Rotterdam were eligible for participation in the study. Around the ages of 10 years, all children and their parents were invited to visit our research centre in the Erasmus MC Sophia Children's Hospital to participate in hands-on measurements, advanced imaging modalities, behavioural observations and biological sample collection. [17]. For the current study, cross-sectional information was obtained on allergic sensitization and allergy. The study has been approved by the Medical Ethical Committee of the Erasmus Medical Center, Rotterdam, the Netherlands (MEC2012-165). Written informed consent was obtained from either parents or legal guardians.

Allergic sensitization and allergy At a median age of 9.8 years (2.5-97.5th percentile, 9.4-10.7), participating children visited our research centre. Inhalant and food allergic sensitization (no, yes) was measured by skin prick tests. Histamine dihydrochloride $(10 \mathrm{mg} / \mathrm{mL})$ and a saline solution $(\mathrm{NaCl}$ $0.9 \%$ ) served as 2 positive controls and 1 negative control, respectively. Inhalant allergens comprised house dust mite 
(HDM) (Dermatophagoides pteronyssinus), 5-grass pollen mixture (Dactylis glomerata, Festuca pratensis, Lolium perenne, Phleum pratense, Poa pratensis), birch (BP) (Betula verrucosa), cat (Felis catus) and dog (Canis familiaris) (ALK-Abelló B.V., Almere, the Netherlands). Homemade food allergen extracts comprised hazelnut, cashew, peanut and peach [8, 9, 37]. Skin responses were recorded 15 min after applying allergens to the skin by measuring the area of the wheal (in $\mathrm{mm}^{2}$ ) using the Precise Automated Area Measurement of Skin Test (PAAMOST) software and considered positive if the area of the wheal was $\geq 40 \%$ of the histamine response [37].

Questions adapted from the International Study of Asthma and Allergies in Childhood (ISAAC) core questionnaires provided information on physician-diagnosed inhalant allergy ('Was your child ever diagnosed with an allergy to pollen (hay fever)/ house dust mite/cat/dog?') (no, yes) and food allergies ('Was your child ever diagnosed by a physician with an allergy to cashew/peanut?') (no/yes) at age 10 years [4]. We further combined allergic sensitization and physician-diagnosed allergy into the following groups: 'no allergic sensitization and no allergy'; 'any allergic sensitization, but no allergy'; 'no allergic sensitization, but any allergy'; and 'any allergic sensitization and any allergy'. Allergic sensitization was defined as being sensitized to at least one inhalant allergen and to have inhalant allergy when diagnosed for at least one inhalant allergen, irrespective of a possible food allergic sensitization or food allergy. Similar considerations were made for food allergic sensitization and food allergy.

Maternal, paternal and child characteristics Information on maternal and paternal age, history of allergy, eczema or asthma (no, yes), BMI, maternal parity (nulliparous, multiparous) and pet keeping (no, yes) was obtained by postal questionnaires completed at enrolment. Information on child's sex, gestational age at birth and birth weight was obtained from obstetric and midwife records at birth. Child's ethnicity was based on the country of birth of the parents and categorized into Western (Dutch, other European, American and Oceanian), Turkish and Moroccan, African (Cape Verdean, other African, Surinamese-Creole and Dutch Antillean) and Asian (Indonesian, other Asian, Surinamese-Hindu and Surinamese-unspecified) as described earlier [14, 39]. We used questionnaires to obtain information on day care attendance (no, yes) at age 1 year and asthma and eczema ever (no, yes) at age 10 years.

Statistical analysis We compared characteristics of children included and not included using independent samples $t$ tests, Mann-Whitney $U$ tests and Pearson's chi-square tests. We used logistic regression or multinomial logistic regression models to examine the associations of maternal, paternal and child characteristics with the risk of allergic sensitization and physician-diagnosed allergy or combined allergic sensitization and physician-diagnosed allergy groups, respectively, at age 10 years. Models were mutually adjusted for all characteristics. Also, analyses with inhalant or food allergic sensitization or allergy as the outcomes were mutually adjusted for each other. To reduce potential bias from missing data and to increase efficiency, we performed a multipleimputation analysis of all characteristics generating 10 independent datasets using the Markov chain Monte Carlo method and calculated pooled estimates. The size or direction of the effect estimates did not materially differ between analyses with imputed data and complete cases only (data not shown). Therefore, we present results based on imputed analyses only. Measures of association are presented as adjusted odds ratios (aOR) with their $95 \%$ confidence intervals (CI). For association analyses, we applied Bonferroni correction to account for multiple testing, correcting for all fifteen characteristics. We considered a $P$ value of smaller than $0.05 / 15=0.003$ significant. Statistical analyses were performed using SPSS 21.0.0.1 (IBM Corp., Armonk, NY, USA).

\section{Results}

General In total, 7393 children at age 10 years were included in the study. Twins ( $n=185)$ and children without data on allergic sensitization or allergy ( $n=1737)$ were excluded, leaving a total of 5471 children for the analyses (Supplementary Figure).

Maternal, paternal and child characteristics are presented in Tables 1 and 2 and Supplementary Table 1. Inhalant or food allergic sensitization was present in $32.2 \%(n=1309)$ and $7.1 \%(n=288)$ of the children at age 10 years, respectively. More specifically, children were most frequently sensitized to house dust mite (HDM) $(20.2 \% ; n=823)$ for inhalant allergens and hazelnut $(4.1 \% ; n=167)$ for food allergens. Physician-diagnosed inhalant or food allergy was present in $12.4 \%(n=586)$ and $2.3 \%(n=104)$ of the children at age 10 years, respectively, with HDM allergy giving the highest percentage. $(8.0 \% ; n=381)$. Children who were not included in the study, had a lower gestational age at birth, were more often of non-European origin, attended day care more often and less often had eczema than those included in the study. Furthermore, their mothers and fathers were younger and more often of non-European origin, and their mothers had higher parity and BMI at enrolment (Supplementary Table 2).

Allergic sensitization Maternal and paternal history of allergy, eczema or asthma was associated with an increased risk of child's allergic sensitization (aOR, 95\% CI 1.44, 1.23-1.70 and $1.59,1.30-1.94$, respectively) (Table 3 ), which applied to all specific inhalant allergens(Supplementary Table 3). Pet keeping during pregnancy was only associated with a decreased risk of grass pollen sensitization $(0.66,0.52-0.83)$. Female children had a decreased risk of inhalant allergic 
Table 1 Characteristics of mothers and fathers

\begin{tabular}{lll}
\hline & $n=5471$ & \\
\cline { 2 - 3 } & Mother & Father \\
\hline Age at enrolment (years) ${ }^{\#}$ & $31.0(4.9)$ & $33.5(5.6)$ \\
History of allergy, eczema or asthma, yes (\%) & $39.0(2134)$ & $34.3(1874)$ \\
Parity, $\geq 1(\%)$ & $42.6(2332)$ & - \\
Pet keeping during pregnancy, yes $(\%)$ & $34.5(1888)$ & - \\
Body mass index at enrolment $\left(\mathrm{kg} / \mathrm{m}^{2}\right)^{\dagger}$ & $23.7(18.9-35.6)$ & \\
Ethnic origin $(\%)$ & & \\
Western & $70.7(3868)$ & \\
Turkish and Moroccan & $10.9(599)$ & \\
African & $10.3(561)$ & \\
Asian & $8.1(443)$ & \\
\hline
\end{tabular}

Values are ${ }^{\#}$ means (SD), ${ }^{\dagger}$ medians (2.5-97.5th percentile) or percentages (absolute numbers) and based on imputed data

sensitization $(0.69,0.59-0.80)$, except for dog allergic sensitization. Children with African ethnicity had an increased risk of inhalant allergic sensitization (1.47, 1.14-1.88), except cat and dog. Asthma and eczema ever at age 10 years were associated with an increased risk of almost all inhalant allergic sensitizations $(1.65,1.26-2.17$ and $2.01,1.68-2.41$, respectively).

For the outcome of food allergic sensitization, only eczema ever at age 10 years was consistently associated with an increased risk of sensitization to any food allergen $(2.09,1.44$ 3.02 ) (Table 3$)$, specifically for cashew (2.93, 1.49-5.75), peanut $(2.22,1.36-3.62)$ and peach $(1.77,1.09-2.88)$ (Supplementary Table 4). No consistent associations of other characteristics with allergic sensitization were found.

Allergy Maternal or paternal history of allergy, eczema or asthma was associated with increased risks of physiciandiagnosed inhalant allergy $(1.43,1.15-1.78$ and 1.69, 1.312.18 , respectively) (Table 4), which specifically comprised almost all inhalant allergies (Supplementary Table 4). Asthma ever and eczema ever at age 10 years were associated with an increased risk of physician-diagnosed inhalant allergy (4.60, 3.55-5.96 and 2.42, 1.94-3.03, respectively), with the highest risk of HDM allergy $(6.06,4.53-8.10)$ and dog allergy (5.95, 3.83-9.24) (Supplementary Table 5).

Only eczema ever at age 10 years was consistently associated with an increased risk of physician-diagnosed food allergy $(5.38,3.04-9.52)$, with the highest risk for cashew (7.36, 3.20-16.94) and peanut (5.58, 3.08-10.10) (Supplementary Table 6). No associations of other characteristics with physician-diagnosed allergy to any allergen in the children were found.

Allergic sensitization and physician-diagnosed allergy combined Maternal and paternal history of allergy, eczema or asthma was associated with increased risks of children with 'any allergic sensitization and no physician diagnosed allergy' (1.44, 1.19-1.74 and 1.65, 1.34-2.04 for mothers and fathers, respectively) and with 'any allergic sensitization and any physician diagnosed allergy' $(1.73,1.31-2.28$ and 2.07, 1.562.75 for mother and fathers, respectively), compared with no parental history of allergy, eczema or allergy and no allergic sensitization and physician-diagnosed allergy (Table 5). Being a child with African ethnicity was consistently associated with all three combinations, with highest OR for 'no allergic sensitization but any allergy' (4.99, 2.24-11.1) Asthma ever at 10 years was associated with increased risk of children with 'any allergic sensitization and any physician diagnosed allergy' $(5.14,3.65-7.23)$. Eczema ever at 10 years of age was consistently associated with all three combinations, with highest OR for children with 'any allergic sensitization and any physician-diagnosed allergy' (3.96, 2.95-5.31). Parity was associated with 'any allergic sensitization, without allergy' $(0.78,0.64-0.96)$. No consistent associations of other characteristics with combined allergic sensitization and physician-diagnosed allergy were found.

\section{Discussion}

This large study showed high presences of inhalant and food allergic sensitizations and physician-diagnosed allergies in this group of Dutch children at age 10 years. Maternal and paternal history of allergy, asthma and eczema and child's current asthma and eczema were most consistently associated with increased risks of allergic sensitization to inhalant and food allergens, physician-diagnosed allergies or combined groups, while female sex of the child was associated with decreased risks of some of these outcomes.

The percentage of sensitization to inhalant sensitization was $32 \%$ in our study. Earlier reports on inhalant sensitization in children in large cross-sectional studies found a prevalence rate 
Table 2 Characteristics of children

\begin{tabular}{|c|c|}
\hline & $n=5471$ \\
\hline Sex, female $(\%)$ & $50.2(2747)$ \\
\hline Gestational age at birth (weeks) ${ }^{\dagger}$ & $40.1(35.7-42.3)$ \\
\hline Birth weight (grams) ${ }^{\#}$ & $3439(555)$ \\
\hline \multicolumn{2}{|l|}{ Ethnic origin $(\%)$} \\
\hline Western & $70.7(3868)$ \\
\hline Turkish and Moroccan & $10.9(599)$ \\
\hline African & $10.3(561)$ \\
\hline Asian & $8.1(443)$ \\
\hline Day care attendance until age 1 year, yes $(\%)$ & $56.9(3111)$ \\
\hline Asthma ever at age 10 years, yes $(\%)$ & $10.9(595)$ \\
\hline Eczema ever at age 10 years, yes $(\%)$ & $23.8(1303)$ \\
\hline \multicolumn{2}{|c|}{ Inhalant allergic sensitization at age 10 years, yes $(\%)$} \\
\hline House dust mite & $20.2(823)$ \\
\hline 5 -grass pollen & $16.0(651)$ \\
\hline Birch pollen & $10.7(436)$ \\
\hline Cat & $10.6(430)$ \\
\hline Dog & $4.3(173)$ \\
\hline Any & $32.2(1309)$ \\
\hline \multicolumn{2}{|l|}{ Food allergic sensitization at age 10 years, yes (\%) } \\
\hline Hazelnut & $4.1(167)$ \\
\hline Cashew nut & $1.3(53)$ \\
\hline Peanut & $3.2(129)$ \\
\hline Peach & $3.8(155)$ \\
\hline Any & $7.1(288)$ \\
\hline \multicolumn{2}{|c|}{ Physician-diagnosed inhalant allergy at age 10 years, yes (\%) } \\
\hline House dust mite & $8.0(381)$ \\
\hline Hay fever & $7.9(373)$ \\
\hline Cat & $5.0(237)$ \\
\hline Dog & $3.5(164)$ \\
\hline Any & $12.4(586)$ \\
\hline \multicolumn{2}{|c|}{ Physician-diagnosed food allergy at age 10 years, yes (\%) } \\
\hline Cashew nut & $1.4(64)$ \\
\hline Peanut & $2.0(93)$ \\
\hline Any & $2.3(104)$ \\
\hline \multicolumn{2}{|c|}{ Allergic sensitization and allergy combined at age 10 years $(\%)$} \\
\hline No allergic sensitization and no allergy & $66.1(2167)$ \\
\hline Any allergic sensitization, but no allergy & $22.6(741)$ \\
\hline No allergic sensitization, but any allergy & $1.4(46)$ \\
\hline Any allergic sensitization and any allergy & $9.8(322)$ \\
\hline
\end{tabular}

Values are ${ }^{\#}$ means (SD) ${ }^{\dagger}$ medians (2.5-97.5th percentile) or percentages (absolute numbers) and based on imputed data. Data on allergic sensitizations and physician-diagnosed allergies were not imputed

of approximately $40 \%[23,29]$. The prevalence of physiciandiagnosed allergy to HDM, hay fever and any pet in the current study was $8.0 \%, 7.9 \%$ and $12.4 \%$, respectively. Higher prevalence for allergy to HDM and grass pollen was found in a recent Polish study among children at age 7 years $(13.5 \%$ and $11.8 \%$, respectively) [34]. In this group of children aged
Table 3 Associations of maternal, paternal and child characteristics with allergic sensitizations in children at age 10 years

Odds ratio $(95 \% \mathrm{CI})$ for allergic sensitization

\begin{tabular}{ll}
\hline Any inhalant & a \\
$n=4061$ & Any food $^{\mathrm{b}}$ \\
$n=4051$
\end{tabular}

Maternal characteristics

Age at enrolment

Per 1-unit increase $\quad 1.03(1.00,1.05)^{*} \quad 0.98(0.93,1.02)$

History of allergy, eczema or asthma

$\begin{array}{lll}\text { No } & \text { Reference } & \text { Reference } \\ \text { Yes } & 1.44(1.23,1.70)^{* *} & 1.18(0.84,1.67)\end{array}$

Parity

0 Reference Reference

$\geq 1 \quad 0.89(0.75,1.05) \quad 1.01(0.72,1.43)$

Pet keeping during pregnancy

No Reference Reference

Yes $\quad 0.77(0.64,0.92)^{*} \quad 0.81(0.55,1.20)$

Body mass index at enrolment

Per 1-unit increase $\quad 1.00(0.98,1.02) \quad 1.01(0.97,1.05)$

Paternal characteristics

Age at enrolment

Per 1-unit increase $\quad 0.98(0.96,1.01) \quad 1.02(0.98,1.06)$

History of allergy, eczema or asthma

No Reference Reference

Yes $\quad 1.59(1.30,1.94)^{* *} \quad 1.19(0.83,1.71)$

Body mass index at enrolment

Per 1-unit increase $\quad 1.01(0.98,1.04) \quad 1.00(0.94,1.07)$

Child characteristics

Sex

Male Reference Reference

Female $\quad 0.69(0.59,0.80) * * \quad 1.13(0.82,1.55)$

Gestational age at birth

Per 1-unit increase $\quad 1.03(0.98,1.09) \quad 0.98(0.87,1.09)$

Birth weight

Per 500-unit increase $\quad 0.97(0.89,1.06) \quad 1.00(0.83,1.21)$

Ethnic origin

Western Reference Reference

Turkish and Moroccan $\quad 1.05(0.80,1.37) \quad 1.06(0.59,1.88)$

African $\quad 1.47(1.14,1.88)^{* *} \quad 1.09(0.67,1.77)$

Asian $\quad 1.15(0.87,1.53) \quad 1.09(0.63,1.91)$

Day care attendance until age 1 year

$\begin{array}{lll}\text { No } & \text { Reference } & \text { Reference } \\ \text { Yes } & 0.90(0.71,1.13) & 0.94(0.62,1.41) \\ \text { Asthma ever at age 10 years } & & \\ \text { No } & \text { Reference } & \text { Reference } \\ \text { Yes } & 1.65(1.26,2.17)^{* * *} & 1.13(0.68,1.87) \\ \text { Eczema ever at age 10 years } & & \\ \text { No } & \text { Reference } & \text { Reference } \\ \text { Yes } & 2.01(1.68,2.41)^{* * *} & 2.09(1.44,3.02)^{* *}\end{array}$

Values are odds ratios (95\% confidence interval) from logistic regression models based on imputed data. Models are adjusted for all characteristics.

${ }^{\mathrm{a}}$ Additionally adjusted for food allergic sensitization. ${ }^{\mathrm{b}}$ Additionally adjusted for inhalant allergic sensitization. $* P$ value $<0.05$. $* * P$ value $<$ 0.003 
Table 4 Associations of maternal, paternal and child characteristics with physiciandiagnosed allergies in children at age 10 years
Odds ratio $(95 \% \mathrm{CI})$ for physician-diagnosed allergy

\begin{tabular}{ll}
\hline Any inhalant & Any food $^{\mathrm{b}}$ \\
$n=4725$ & $n=4621$
\end{tabular}

$0.97(0.94,1.01)$

$1.03(0.96,1.11)$

Per 1-unit increase

$n=4621$

\begin{tabular}{|c|c|c|}
\hline \multicolumn{3}{|l|}{ Maternal characteristics } \\
\hline \multicolumn{3}{|l|}{ Age at enrolment } \\
\hline Per 1-unit increase & $0.97(0.94,1.01)$ & $1.03(0.96,1.11)$ \\
\hline \multicolumn{3}{|c|}{ History of allergy, eczema or asthma } \\
\hline No & Reference & Reference \\
\hline Yes & $1.43(1.15,1.78)^{* *}$ & $1.01(0.60,1.71)$ \\
\hline \multicolumn{3}{|l|}{ Parity } \\
\hline 0 & Reference & Reference \\
\hline$\geq 1$ & $0.83(0.65,1.05)$ & $0.93(0.55,1.59)$ \\
\hline \multicolumn{3}{|c|}{ Pet keeping during pregnancy } \\
\hline No & Reference & Reference \\
\hline Yes & $0.82(0.64,1.05)$ & $0.92(0.52,1.62)$ \\
\hline \multicolumn{3}{|c|}{ Body mass index at enrolment } \\
\hline Per 1-unit increase & $1.00(0.97,1.03)$ & $0.98(0.92,1.05)$ \\
\hline \multicolumn{3}{|l|}{ Paternal characteristics } \\
\hline \multicolumn{3}{|l|}{ Age at enrolment } \\
\hline Per 1-unit increase & $1.01(0.98,1.04)$ & $1.00(0.93,1.06)$ \\
\hline \multicolumn{3}{|c|}{ History of allergy, eczema or asthma } \\
\hline No & Reference & Reference \\
\hline Yes & $1.69(1.31,2.18)^{* *}$ & $1.50(0.83,2.68)$ \\
\hline \multicolumn{3}{|c|}{ Body mass index at enrolment } \\
\hline Per 1-unit increase & $1.00(0.96,1.05)$ & $0.96(0.87,1.06)$ \\
\hline \multicolumn{3}{|l|}{ Child characteristics } \\
\hline \multicolumn{3}{|l|}{ Sex } \\
\hline Male & Reference & Reference \\
\hline Female & $0.68(0.55,0.84)^{* *}$ & $1.12(0.68,1.83)$ \\
\hline \multicolumn{3}{|l|}{ Gestational age at birth } \\
\hline Per 1-unit increase & $0.99(0.92,1.06)$ & $0.96(0.81,1.13)$ \\
\hline \multicolumn{3}{|l|}{ Birth weight } \\
\hline Per 500-unit increase & $1.02(0.90,1.15)$ & $0.97(0.73,1.28)$ \\
\hline \multicolumn{3}{|l|}{ Ethnic origin } \\
\hline Western & Reference & Reference \\
\hline Turkish and Moroccan & $1.50(1.02,2.21)^{*}$ & $0.45(0.14,1.53)$ \\
\hline African & $1.39(0.98,1.97)$ & $1.67(0.82,3.43)$ \\
\hline Asian & $1.40(0.95,2.06)$ & $1.97(0.89,4.35)$ \\
\hline \multicolumn{3}{|c|}{ Day care attendance until age 1 year } \\
\hline No & Reference & Reference \\
\hline Yes & $1.03(0.72,1.47)$ & $0.84(0.41,1.74)$ \\
\hline \multicolumn{3}{|c|}{ Asthma ever at age 10 years } \\
\hline No & Reference & Reference \\
\hline Yes & $4.60(3.55,5.96)^{* *}$ & $1.70(0.89,3.24)$ \\
\hline \multicolumn{3}{|c|}{ Eczema ever at age 10 years } \\
\hline No & Reference & Reference \\
\hline Yes & $2.42(1.94,3.03)^{* *}$ & $5.38(3.04,9.52)^{* *}$ \\
\hline
\end{tabular}

Values are odds ratios (95\% confidence interval) from logistic regression models based on imputed data. Models are adjusted for all characteristics. ${ }^{\mathrm{a}}$ Additionally adjusted for physician-diagnosed food allergy. ${ }^{\mathrm{b}}$ Additionally adjusted for physician-diagnosed inhalant allergy. $* P$ value $<0.05$. $* * P$ value $<0.003$ 
Table 5 Associations of maternal, paternal and child characteristics with allergic sensitization and physiciandiagnosed allergy combined in children at age 10 years

\begin{tabular}{|c|c|c|c|}
\hline & \multicolumn{3}{|c|}{$\begin{array}{l}\text { Odds ratio }(95 \% \mathrm{CI}) \text { for any allergic sensitization and any physician-diagnosed } \\
\text { allergy combined }\end{array}$} \\
\hline & $\begin{array}{l}\text { Any allergic sensitization, } \\
\text { but no allergy }\end{array}$ & $\begin{array}{l}\text { No allergic sensitization, } \\
\text { but any allergy }\end{array}$ & $\begin{array}{l}\text { Any allergic sensitization } \\
\text { and any allergy }\end{array}$ \\
\hline & $n=741$ & $n=46$ & $n=322$ \\
\hline \multicolumn{4}{|l|}{ Maternal characteristics } \\
\hline \multicolumn{4}{|l|}{ Age at enrolment } \\
\hline Per 1-unit increase & $1.03(1.00,1.06)$ & $0.95(0.88,1.03)$ & $0.99(0.95,1.03)$ \\
\hline \multicolumn{4}{|c|}{ History of allergy, eczema or asthma } \\
\hline No & Reference & Reference & Reference \\
\hline Yes & $1.44(1.19,1.74)^{* *}$ & $1.18(0.57,2.47)$ & $1.73(1.31,2.28)^{* *}$ \\
\hline \multicolumn{4}{|l|}{ Parity } \\
\hline 0 & Reference & Reference & Reference \\
\hline$\geq 1$ & $0.83(0.69,1.01)^{*}$ & $0.81(0.41,1.62)$ & $0.83(0.62,1.12)$ \\
\hline \multicolumn{4}{|c|}{ Pet keeping during pregnancy } \\
\hline No & Reference & Reference & Reference \\
\hline Yes & $0.78(0.64,0.96)^{*}$ & $0.96(0.46,2.03)$ & $0.74(0.53,1.02)$ \\
\hline \multicolumn{4}{|c|}{ Body mass index at enrolment } \\
\hline Per 1-unit increase & $1.00(0.98,1.03)$ & $1.04(0.97,1.11)$ & $0.97(0.93,1.01)$ \\
\hline \multicolumn{4}{|l|}{ Paternal characteristics } \\
\hline \multicolumn{4}{|l|}{ Age at enrolment } \\
\hline Per 1-unit increase & $0.98(0.96,1.00)$ & $1.01(0.93,1.08)$ & $1.01(0.97,1.05)$ \\
\hline \multicolumn{4}{|c|}{ History of allergy, eczema or asthma } \\
\hline No & Reference & Reference & Reference \\
\hline Yes & $1.65(1.34,2.04)^{* *}$ & $1.44(0.61,3.43)$ & $2.07(1.56,2.75)^{* *}$ \\
\hline \multicolumn{4}{|c|}{ Body mass index at enrolment } \\
\hline Per 1-unit increase & $1.01(0.98,1.04)$ & $0.97(0.87,1.09)$ & $1.00(0.95,1.06)$ \\
\hline \multicolumn{4}{|l|}{ Child characteristics } \\
\hline \multicolumn{4}{|l|}{ Sex } \\
\hline Male & Reference & Reference & Reference \\
\hline Female & $0.71(0.59,0.84)^{* *}$ & $0.68(0.37,1.26)$ & $0.62(0.47,0.80)^{* *}$ \\
\hline \multicolumn{4}{|l|}{ Gestational age at birth } \\
\hline Per 1-unit increase & $1.02(0.96,1.08)$ & $0.93(0.76,1.13)$ & $1.03(0.94,1.14)$ \\
\hline \multicolumn{4}{|l|}{ Birth weight } \\
\hline Per 500-unit increase & $0.99(0.89,1.09)$ & $1.01(0.71,1.44)$ & $0.99(0.85,1.15)$ \\
\hline \multicolumn{4}{|l|}{ Ethnic origin } \\
\hline Western & Reference & Reference & Reference \\
\hline Turkish and Moroccan & $1.00(0.70,1.42)$ & $1.69(0.58,4.94)$ & $1.43(0.88,2.34)$ \\
\hline African & $1.69(1.25,2.30)^{* *}$ & $4.99(2.24,11.1)^{* *}$ & $1.88(1.22,2.90) *$ \\
\hline Asian & $1.34(0.95,1.88)$ & $3.08(1.18,8.06) *$ & $1.61(1.01,2.57)^{*}$ \\
\hline \multicolumn{4}{|c|}{ Day care attendance until age 1 year } \\
\hline No & Reference & Reference & Reference \\
\hline Yes & $0.81(0.64,1.03)$ & $0.53(0.23,1.21)$ & $0.86(0.58,1.28)$ \\
\hline \multicolumn{4}{|c|}{ Asthma ever at age 10 years } \\
\hline No & Reference & Reference & Reference \\
\hline Yes & $0.85(0.59,1.21)$ & $3.07(1.45,6.50)^{*}$ & $5.14(3.65,7.23)^{* *}$ \\
\hline \multicolumn{4}{|c|}{ Eczema ever at age 10 years } \\
\hline No & Reference & Reference & Reference \\
\hline Yes & $2.37(1.93,2.91)^{* *}$ & $3.25(1.69,6.23)^{* *}$ & $3.96(2.95,5.31)^{* *}$ \\
\hline
\end{tabular}

Values are odds ratios (95\% confidence interval) from multinomial logistic regression models based on imputed data. Reference group is children without any allergic sensitization or physician-diagnosed allergy $(n=2167)$. Models are adjusted for all characteristics. $* P$ value $<0.05$. $* * P$ value $<0.003$
10 years, we also found that girls were consistently less likely than boys to develop sensitization to inhalant allergens, as well as physician-diagnosed inhalant allergy at the age of 10 years (OR 0.69 and 0.68). This agrees with the findings of previous European studies [5, 30].

Furthermore, the percentage of sensitization to food allergens including hazelnut, cashew, peanut and peach was $4.1 \%$,
$1.3 \%, 3.2 \%$ and $3.8 \%$, respectively, in our study. Previous studies in Europe showed similar prevalence [26], including sensitization to food allergens (all kind of allergens) of $4.1 \%$ in children at age 10 years $(n=969)$ in a birth cohort study on the Isle of Wight (UK) [38].

Allergic sensitization to food allergens occurs often without clinical relevance, and therefore, physician-diagnosed 
food allergy is of special interest. The presence of physiciandiagnosed allergy to cashew, peanut or any food was $1.4 \%$, $2.0 \%$ and $2.3 \%$, respectively, in our study, comparable with recent results on prevalence of tree nut allergy in Europe by McWilliam et al. (0.2-4.9\%) [19].

We found several associations between history of allergy in the parents and sensitization or physician-diagnosed allergy in the children. A history of allergy, eczema or asthma of the parents showed associations with increased risk of sensitization to inhalant allergens and doctor-diagnosed inhalant allergy in children at age 10 years. These parental effects on inhalant allergy in children are well known in literature $[2,5]$.

We demonstrated that pet exposure during pregnancy was negatively associated only with inhalant sensitization in children at age 10 years but significance disappeared after Bonferroni correction. It has previously been demonstrated that pet avoidance is associated with specific IgE responses and increased specific IgE levels [29, 37]. Furthermore, several prospective studies indicated that living with a pet reduces the risk of becoming sensitized to that pet [33], while other studies did not $[13,32]$. Therefore, the relationship between the development of sensitization and exposure to pet allergens remains controversial.

Neither history of the parents nor pet keeping during pregnancy nor day care of the child until age 1 was associated with sensitization to food allergens or physician-diagnosed food allergy, while eczema ever at age 10 years had a large effect on sensitization to the tested food allergens (hazelnut, cashew, peanut and peach) and physician-diagnosed food allergy at 10 years.

Asthma and eczema ever in children in the current study at age 10 were strongly associated with physician-diagnosed allergy to inhalant allergens. This is in line with a study by Arshad et al. in a birth cohort of 1456 children, reporting that $80 \%$ of the children at age 4 years, with positive skin test to more than 4 allergens, had asthma, eczema and/or rhinitis compared with $20 \%$ of non-atopic children [3].

Atopic dermatitis seems to play an important role in the development of food allergy. Recent findings in the HealthNuts study found $26 \%$ of the children at age 2 years with atopic dermatitis had food allergy [27]. In the current study, high ORs were found for having ever eczema and physician-diagnosed cashew allergy (OR (95\% CI), 7.87 (3.45-17.92)). In an earlier study in the Netherlands, van der Valk et al. found a high number of positive challenges in cashew-sensitized children (76.4\%) [36]. Apparently, cashew is a common allergen in the Netherlands and becomes symptomatic especially in combination with eczema at a young age.

We found an association between children with African ethnicity and sensitization to inhalant allergens. Some other studies found that ethnicity is a risk factor for the development of sensitization to foods [29] and inhalant allergens [18], but this might be explained rather by environmental than genetic factors [40].
The major strength of this study is the use of a populationbased prospective study design from fetal life onwards with a large number of participants and detailed information on parental and child characteristics and allergic sensitization and allergy. We were able to study multiple potential associated maternal, paternal and child characteristics. Previously, we observed no associations of duration and exclusiveness of breastfeeding with any allergic sensitization or allergy, or combination of these outcomes at age 10 years, and therefore not included breastfeeding in our models [11]. Furthermore, in the same population, timing and introduction of allergenic foods, e.g. cow's milk, were studied, and no effects were seen in allergic sensitization and physician-diagnosed allergy, so these outcomes were also not included in our model [10].

Some methodological limitations should be considered. First, selection bias in longitudinal studies mainly arises due to follow-up. Characteristics of non-included subjects differed from those included in the study. Firstly, this may affect the percentage of estimated prevalence of allergic sensitization and physician-diagnosed allergy in the study. The children in the non-included group had a slightly shorter gestational age at birth. The latter is earlier described as being negatively associated with food allergy in children [20]. Furthermore, the included group had a higher percentage (not significant) of asthma and eczema ever at age 10 compared with the non-included group. The included group might be somewhat more atopic and consequently might show higher numbers for allergic sensitization. Although the differences between included and non-included children may affect the generalizability of our results, it is unlikely that these differences led to significant selection bias in this study. Second, we used parental questionnaires to obtain data on child's allergy and eczema, which may have led to non-differential misclassification of these outcomes, specifically food allergy. This probably led to an underestimation of the effect estimates. However, questionnaires consisted of commonly used questions that reflect the prevalence of allergy in young children at the population level [4, 12]. Third, we aimed to reduce potential bias due to missing data using multiple imputation methods assuming that missing data were missing at random. However, it remains difficult to quantify the effect of non-random missing data, partly due to computational limitations and current statistical software availability. Fourth, for measuring allergic sensitization, we selected a panel of common inhalant and food allergens relevant to children of age 10 years. Apparently, we selected allergens that were relevant for children of this age, with high sensitization levels. Milk and egg allergens were not considered because of low sensitization and allergy rates at this age [28]. Finally, as in any observational study, residual confounding due to insufficiently or unmeasured confounders might be an issue. 
Although progress has been made in defining endotypes for asthma, definitions for food and inhalant allergy lag behind. Recently, Muraro et al. suggested to combine all current known predictive markers to understand and differentiate the distinct endotypes of disease among individuals having a similar phenotype and assist with the ability to personalize treatment and prevention to improve health outcome [21, 22]. The current study underlines the relation between several known predictive markers. Furthermore, development of allergy in children is often called 'the atopic march'. The results in this cohort study on children from birth until age 10 years confirm the strong relation between eczema, asthma and inhalant and food allergy, which often starts with atopic dermatitis at a very young age [7]. Early recognition of atopic dermatitis and consequent treatment might have effect on further development of atopic diseases [31].

In conclusion, we described the results of a large population-based cohort study on the presence of allergic sensitization and physician-diagnosed allergy in Dutch children at age 10 years. We found strong effect estimates for the associations of parental history of allergy, eczema or asthma with physician-diagnosed inhalant allergy. Also, eczema ever at age 10 years was a risk factor for the development of physician-diagnosed inhalant and food allergy, and therefore, for children with eczema, a proper and intense guidance by paediatricians is mandatory. Further studies using more detailed information on allergic sensitization and allergy at different time points form early-life onwards are needed to provide better insights in the underlying biological mechanisms.

Acknowledgements The Generation R Study is conducted by the Erasmus Medical Center in close collaboration with the School of Law and the Faculty of Social Sciences at the Erasmus University, Rotterdam; the Municipal Health Service, Rotterdam area; and the Stichting Trombosedienst and Artsenlaboratorium Rijnmond (Star-MDC), Rotterdam. We gratefully acknowledge the contribution of children and their parents, general practitioners, hospitals, midwives and pharmacies in Rotterdam. We gratefully acknowledge the contribution of children and parents, general practitioners, hospitals, midwives and pharmacies in Rotterdam.

Sources of financial support The Generation R Study is made possible by financial support from the Erasmus MC, Rotterdam; the University Medical Center Rotterdam; and the Netherlands Organization for Health Research and Development. Dr. Vincent W.V. Jaddoe received grants from the Netherlands Organization for Health Research and Development (VIDI o16.136.3610) and the European Research Council (ERC-2014-CoG-648,916). Dr. Liesbeth Duijts received funding from the European Union's Horizon 2020 research and innovation programme (grant agreement no. 696295 ; 2017) cofunded by ERA-Net on Biomarkers for Nutrition and Health (ERA HDHL) and ZonMW, the Netherlands (no. 529051014; 2017) (ALPHABET project). The project received funding from the European Union's Horizon 2020 research and innovation programme (LIFECYCLE project, grant agreement no. 733206; 2016).
Authors' contributions NJ, NE, SMB, JV, SP and LD contributed to the conception and design, acquisition of data, analyses and interpretation of the data; drafted the article; revised it critically for important intellectual content; and gave final approval of the version to be published. VJ, JJ and RG contributed to the conception and design and acquisition of data, revised the drafted manuscript critically for important intellectual content and gave final approval of the version to be published.

\section{Compliance with ethical standards}

Ethical approval All procedures performed in studies involving human participants were in accordance with the ethical standards of the institutional and/or national research committee and with the 1964 Helsinki declaration and its later amendments or comparable ethical standards.

Conflict of interest The authors declare that they have no conflict of interest.

Informed consent Informed consent was obtained from all individual participants included in the study.

Disclaimer The researchers are independent from the funders. The study sponsors had no role in the study design, data collection, data analysis, interpretation of data and preparation, review or approval of the manuscript.

Open Access This article is distributed under the terms of the Creative Commons Attribution 4.0 International License (http:// creativecommons.org/licenses/by/4.0/), which permits unrestricted use, distribution, and reproduction in any medium, provided you give appropriate credit to the original author(s) and the source, provide a link to the Creative Commons license, and indicate if changes were made.

\section{References}

1. Amat F, Saint-Pierre P, Bourrat E, Nemni A, Couderc R, BoutmyDeslandes E, Sahraoui F, Panse I, Bagot M, Fouere S, Just J (2015) Early-onset atopic dermatitis in children: which are the phenotypes at risk of asthma? Results from the ORCA cohort. PLoS One 10: e0131369

2. Arabkhazaeli A, Ahmadizar F, Leusink M, Arets HGM, Raaijmakers JAM, Uiterwaal CS, van der Ent CK, Maitland-van der Zee AH, Vijverberg SJH (2017) The association between an genetic risk score for allergy and the risk of developing allergies in childhood - results of the WHISTLER cohort. Pediatr Allergy Immunol

3. Arshad SH, Tariq SM, Matthews S, Hakim E (2001) Sensitization to common allergens and its association with allergic disorders at age 4 years: a whole population birth cohort study. Pediatrics 108 : E33

4. Asher MI, Keil U, Anderson HR, Beasley R, Crane J, Martinez F, Mitchell EA, Pearce N, Sibbald B, Stewart AW, Strachan D, Weiland SK, Williams HC (1995) International Study of Asthma and Allergies in Childhood (ISAAC): rationale and methods. Eur Respir J 8:483-491

5. Ballardini N, Kull I, Lind T, Hallner E, Almqvist C, Ostblom E, Melen E, Pershagen G, Lilja G, Bergstrom A, Wickman M (2012) Development and comorbidity of eczema, asthma and rhinitis to age 12: data from the BAMSE birth cohort. Allergy 67:537-544

6. Brugman E, Meulmeester JF, Spee-van der Wekke A, Beuker RJ, Radder JJ, Verloove-Vanhorick SP (1998) Prevalence of self- 
reported food hypersensitivity among school children in the Netherlands. Eur J Clin Nutr 52:577-581

7. Brunner PM, Silverberg JI, Guttman-Yassky E, Paller AS, Kabashima K, Amagai M, Luger TA, Deleuran M, Werfel T, Eyerich K, Stingl G, Councilors of the International Eczema C (2017) Increasing comorbidities suggest that atopic dermatitis is a systemic disorder. J Invest Dermatol 137:18-25

8. de Groot H, de Jong NW, Vuijk MH, Gerth van Wijk R (1996) Birch pollinosis and atopy caused by apple, peach, and hazelnut; comparison of three extraction procedures with two apple strains. Allergy 51:712-718

9. de Jong NW, van Maaren MS, Vlieg-Boersta BJ, Dubois AE, de Groot H, Gerth van Wijk R (2010) Sensitization to lupine flour: is it clinically relevant? Clin Exp Allergy 40:1571-1577

10. Elbert NJ, Kiefte-de Jong JC, Voortman T, Nijsten TEC, de Jong NW, Jaddoe VWV, de Jongste JC, Gerth van Wijk R, Duijts L, Pasmans S (2017) Allergenic food introduction and risk of childhood atopic diseases. PLoS One 12:e0187999

11. Elbert NJ, van Meel ER, den Dekker HT, de Jong NW, Nijsten TEC, Jaddoe VWV, de Jongste JC, Pasmans S, Duijts L (2017) Duration and exclusiveness of breastfeeding and risk of childhood atopic diseases. Allergy 72:1936-1943

12. Flohr C, Weinmayr G, Weiland SK, Addo-Yobo E, AnnesiMaesano I, Björkstén B, Bråbäck L, Büchele G, Chico M, Cooper P, Clausen M, El Sharif N, Martinez Gimeno A, Mathur RS, von Mutius E, Morales Suarez-Varela M, Pearce N, Svabe V, Wong GW, Yu M, Zhong NS, Williams HC, ISAAC Phase Two Study Group (2009) How well do questionnaires perform compared with physical examination in detecting flexural eczema? Findings from the International Study of Asthma and Allergies in Childhood (ISAAC) Phase Two. Br J Dermatol 161:846-853

13. Gabet S, Just J, Couderc R, Seta N, Momas I (2016) Allergic sensitisation in early childhood: patterns and related factors in PARIS birth cohort. Int J Hyg Environ Health 219:792-800

14. Hague/Heerlen T (2014) Statistics Netherlands. Annual report on integration 2014

15. Henriksen L, Simonsen J, Haerskjold A, Linder M, Kieler H, Thomsen SF, Stensballe LG (2015) Incidence rates of atopic dermatitis, asthma, and allergic rhinoconjunctivitis in Danish and Swedish children. J Allergy Clin Immunol 136:360-366 e362

16. Hose AJ, Depner M, Illi S, Lau S, Keil T, Wahn U, Fuchs O, Pfefferle PI, Schmausser-Hechfellner E, Genuneit J, Lauener R, Karvonen AM, Roduit C, Dalphin JC, Riedler J, Pekkanen J, von Mutius E, Ege MJ, Mas, groups Ps (2017) Latent class analysis reveals clinically relevant atopy phenotypes in 2 birth cohorts. $\mathrm{J}$ Allergy Clin Immunol 139:1935-1945 e1912

17. Kooijman MN, Kruithof CJ, van Duijn CM, Duijts L, Franco OH, van IMH, de Jongste JC, Klaver CC, van der Lugt A, Mackenbach JP, Moll HA, Peeters RP, Raat H, Rings EH, Rivadeneira F, van der Schroeff MP, Steegers EA, Tiemeier H, Uitterlinden AG, Verhulst FC, Wolvius E, Felix JF, Jaddoe VW (2016) The Generation R Study: design and cohort update 2017. Eur J Epidemiol 31:12431264

18. Kumar R, Tsai HJ, Hong X, Liu X, Wang G, Pearson C, Ortiz K, Fu M, Pongracic JA, Bauchner H, Wang X (2011) Race, ancestry, and development of food-allergen sensitization in early childhood. Pediatrics 128:e821-e829

19. McWilliam V, Koplin J, Lodge C, Tang M, Dharmage S, Allen K (2015) The prevalence of tree nut allergy: a systematic review. Curr Allergy Asthma Rep 15:54

20. Mitselou N, Hallberg J, Stephansson O, Almqvist C, Melen E, Ludvigsson JF (2018) Cesarean delivery, preterm birth, and risk of food allergy: nationwide Swedish cohort study of more than 1 million children. J Allergy Clin Immunol 142:1510-1514.e2

21. Muraro A, Lemanske RF Jr, Castells M, Torres MJ, Khan D, Simon HU, Bindslev-Jensen C, Burks W, Poulsen LK, Sampson HA,
Worm M, Nadeau KC (2017) Precision medicine in allergic disease-food allergy, drug allergy, and anaphylaxis-PRACTALL document of the European Academy of Allergy and Clinical Immunology and the American Academy of Allergy, Asthma and Immunology. Allergy 72:1006-1021

22. Muraro A, Lemanske RF Jr, Hellings PW, Akdis CA, Bieber T, Casale TB, Jutel M, Ong PY, Poulsen LK, Schmid-Grendelmeier P, Simon HU, Seys SF, Agache I (2016) Precision medicine in patients with allergic diseases: airway diseases and atopic dermatitis-PRACTALL document of the European Academy of Allergy and Clinical Immunology and the American Academy of Allergy, Asthma \& Immunology. J Allergy Clin Immunol 137: $1347-1358$

23. Nwaru BI, Hickstein L, Panesar SS, Roberts G, Muraro A, Sheikh A, Allergy EF, Anaphylaxis Guidelines G (2014) Prevalence of common food allergies in Europe: a systematic review and metaanalysis. Allergy 69:992-1007

24. O'Connell EJ (2004) The burden of atopy and asthma in children. Allergy 59(Suppl 78):7-11

25. Pawankar R, Baena-Cagnani CE, Bousquet J, Walter Canonica G, Cruz AA, Kaliner MA, Lanier BQ (2008) State of world allergy report 2008 allergy and chronic respiratory diseases. World Allergy Organ J 1:S1

26. Pereira B, Venter C, Grundy J, Clayton CB, Arshad SH, Dean T (2005) Prevalence of sensitization to food allergens, reported adverse reaction to foods, food avoidance, and food hypersensitivity among teenagers. J Allergy Clin Immunol 116:884-892

27. Peters RL, Allen KJ, Dharmage SC, Lodge CJ, Koplin JJ, Ponsonby AL, Wake M, Lowe AJ, Tang MLK, Matheson MC, Gurrin LC, HealthNuts s (2015) Differential factors associated with challenge-proven food allergy phenotypes in a population cohort of infants: a latent class analysis. Clin Exp Allergy 45:953-963

28. Roberts G, Zhang H, Karmaus W, Raza A, Scott M, Matthews S, Kurukulaaratchy RJ, Dean T, Arshad SH (2012) Trends in cutaneous sensitization in the first 18 years of life: results from the 1989 Isle of Wight birth cohort study. Clin Exp Allergy 42:1501-1509

29. Salo PM, Arbes SJ Jr, Jaramillo R, Calatroni A, Weir CH, Sever ML, Hoppin JA, Rose KM, Liu AH, Gergen PJ, Mitchell HE, Zeldin DC (2014) Prevalence of allergic sensitization in the United States: results from the National Health and Nutrition Examination Survey (NHANES) 2005-2006. J Allergy Clin Immunol 134:350-359

30. Schmitz R, Ellert U, Kalcklosch M, Dahm S, Thamm M (2013) Patterns of sensitization to inhalant and food allergens - findings from the German Health Interview and Examination Survey for Children and Adolescents. Int Arch Allergy Immunol 162:263-270

31. Schneider L, Hanifin J, Boguniewicz M, Eichenfield LF, Spergel JM, Dakovic R, Paller AS (2016) Study of the atopic march: development of atopic comorbidities. Pediatr Dermatol 33:388-398

32. Schoos AM, Chawes BL, Jelding-Dannemand E, Elfman LB, Bisgaard H (2016) Early indoor aeroallergen exposure is not associated with development of sensitization or allergic rhinitis in highrisk children. Allergy 71:684-691

33. Simpson A, Custovic A (2005) Pets and the development of allergic sensitization. Curr Allergy Asthma Rep 5:212-220

34. Sybilski AJ, Zalewska M, Furmanczyk K, Lipiec A, Krzych-Falta E, Samolinski B (2015) The prevalence of sensitization to inhalant allergens in children with atopic dermatitis. Allergy Asthma Proc 36:e81-e85

35. van Amsterdam JG, Bischoff EW, Hady M, Opperhuizen A, Steerenberg PA (2004) The prevalence of allergic sensitisation in immigrant children in the Netherlands. Int Arch Allergy Immunol 133:248-254

36. van der Valk JP, Gerth van Wijk R, Dubois AE, de Groot H, Reitsma M, Vlieg-Boerstra B, Savelkoul HF, Wichers HJ, de Jong NW (2016) Multicentre double-blind placebo-controlled food 
challenge study in children sensitised to cashew nut. PLoS One 11: $\mathrm{e} 0151055$

37. van der Valk JP, Gerth van Wijk R, Hoorn E, Groenendijk L, Groenendijk IM, de Jong NW (2015) Measurement and interpretation of skin prick test results. Clin Transl Allergy 6:8

38. Venter C, Patil V, Grundy J, Glasbey G, Twiselton R, Arshad SH, Dean T (2016) Prevalence and cumulative incidence of food hypersensitivity in the first 10 years of life. Pediatr Allergy Immunol 27: $452-458$

39. Voortman T, van den Hooven EH, Heijboer AC, Hofman A, Jaddoe VW, Franco OH (2015) Vitamin D deficiency in school-age children is associated with sociodemographic and lifestyle factors. J Nutr 145:791-798

40. Yang JJ, Burchard EG, Choudhry S, Johnson CC, Ownby DR, Favro D, Chen J, Akana M, Ha C, Kwok PY, Krajenta R, Havstad SL, Joseph CL, Seibold MA, Shriver MD, Williams LK (2008) Differences in allergic sensitization by self-reported race and genetic ancestry. J Allergy Clin Immunol 122(820-827):e829

Publisher's note Springer Nature remains neutral with regard to jurisdictional claims in published maps and institutional affiliations. 